\title{
Illether
}



\section{Alcademilfire feffrede}

gehalten

ant

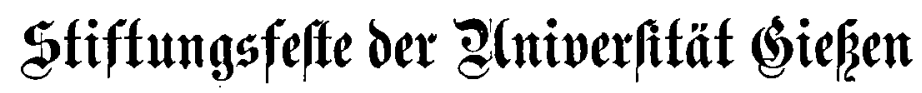

\author{
1. $\mathfrak{I} \mathfrak{H} \mathfrak{l} \mathfrak{i} 188 \mathfrak{\gamma}$ \\ bon \\ Dr. Eerdinand Enattenluridy \\ orbentlidem Brofeffor ber Theologie \\ b. 3. $\Re$ eftor.
}

(Siejen, 1887.

ร. $\mathfrak{A}$ ider'fde $\mathfrak{B} u \mathfrak{d}$ handung. 
